\title{
Effect of Educational Program on Nurses performance About Infection Control for Patients Undergoing Hemodialysis
}

\author{
Samia Moured Morkes ${ }^{1}$, Shalabia El-Sayed Abozead ${ }^{2}$ \& Sahra Zaki Azer ${ }^{3}$. \\ 1 B. Sc.Faculty of nursing, Assiut Unversity, Egypt. \\ 2 Professor of Medical Surgical Nursing, Faculty of Nursing, Assiut University, Egypt. \\ 3 Assistant Professor of Medical Surgical Nursing, Faculty of Nursing, Assiut University, Egypt.
}

\begin{abstract}
Infections account for the second leading cause of mortality among patients with end-stage renal disease. Many of these infections are due to sepsis, primarily arising from the vascular access site. The aims of this study: were to assess nurses' knowledge and practice about infection control during hemodialysis, design of an educational nursing program, implementing \& evaluating the effect of this educational nursing program on infection control in hemodialysis. Setting: This study was conducted in hemodialysis unit at Om El-Kosoar, Assiut University Hospital. Subjects: purposful sample of 55 nurses of both sexes, age ranges from 18 to 60 years. Tools: Self-administed questionnaire sheet, observational checklist and educational nursing program. Results: there was a highly significant difference and improvement as regard knowledge level and practice score for nurses about infection control pre dialysis, intra dialysis and post dialysis after implementing the nursing education program. Conclusion: Poor nurses' knowledge and practices pre program, improve nurses knowledge and practices about infection control post program. Recommendation: Continue nursing training sessions about infection control in hemodialysis unit to reduce the incidence of infection.
\end{abstract}

\section{Keywords: Educational Program, Hemodialysis \& Infection Control.}

\section{Introduction}

Hemodialysis is a medical procedure to remove fluid and waste products from the blood and to correct electrolyte imbalances. This is accomplished using a machine and a dialyzer, also referred to as an "artificial kidney." hemodialysis is used to treat both acute (temporary) and chronic (permanent) kidney failure (Fauci et al., 2012).

Hemodialysis is a process of purifying the blood of a person whose kidneys are not working normally. This type of dialysis achieves the extracorporeal removal of waste products such as creatinine and urea and free water from the blood when the kidneys are in a state of kidney failure (Patel et al., 2010).

Infection is the most common cause of hospitalization and the second most common cause of mortality among hemodialysis (HD) patients, after cardiovascular disease. HD patients are exposed to different types of infection, which include bloodstream infections and localized infections of the vascular access, blood-borne infections with hepatitis B virus (HBV), hepatitis C virus (HCV) and/or human immunodeficiency virus (HIV) and airborne infections like tuberculosis. (Napalkov et al., 2013). Sources of infections could be contaminated water, equipment and environmental surfaces in the treatment area and patients with infections which pose a risk to other nearby patients being treated in the dialysis unit. The increased risk for contracting health-care-associated infections (HAIs) among HD patients are mainly due to, immune compromised status, frequent and prolonged blood exposure during HD treatments through the vascular access and extracorporeal circuit (with many ports and connections), close proximity to other patients during treatment in the HD facility, frequent contact with health-care workers, who frequently move between patients and between machines, frequent hospitalization and surgery, and most importantly, non-adherence or a break in implementation of recommended practices (Rosenthal et al., 2010).

Hemodialysis patients are at a high risk for infection so that; nursing role is essential and important to prevent and control infection at hemodialysis unit include: hand hygiene, use of protective equipment, cleaning and disinfection, handling of disposable supplies and water treatment purity and testing (Loiselle et al., 2011).

\section{Significance of the study}

About (83) patients admitted in hemodialysis unit at Om El-Kosour, Assiut University Hospital according to hospital record 2016. From the researcher's clinical experience it has been observed that patients undergoing dialysis need special nursing care to decrease infection through carrying out performance which control with infection associated with hemodialysis. This study was provide the nurses knowledge and practice about infection control during hemodialysis. 


\section{Aims of the study to}

1. Assess nurses' knowledge \& practice about infection control during hemodialysis.

2. Design an educational nursing program about infection control during hemodialysis.

3. Implement \& evaluate the effect of an educational nursing program about infection control during hemodialysis.

\section{Research hypothesis}

Hemodialysis nurses attending infection control educational nursing program exhibits high mean knowledge and practice or performances post programe than pre program

\section{Research design}

Pre / posttest experimental design was utilized to conduct this study.

\section{Setting:}

The study was conducted in hemodialysis unit at Om El-Kosoar, Assiut University Hospital.

\section{Subjects}

Purposeful sample of 55 nurses of both sexes in hemodialysis unit at Om El-Kosoar / El-Kosea, Assiut University Hospital. Age ranges from 18 to 60 years, 4 nurses missed from present study because they had holidays.

\section{Critera of sample selection}

sample of nurses of both sexes in hemodialysis unit at Om El-Kosoar / El-Kosea, Assiut University Hospital. Age ranges from 18 to 60 years.

Tools of the study

Two tools were utilized to collect data for this study:

Tool (I): Self-administered questionnaire sheet: to assess socio-demographic data \& knowledge related to hemodialysis about infection control. This tool consists of three parts.

Part (1): Socio demographic data for nurses as (age, gender, level of education, \& year of experience, attained training in the field of specialization, training programmer, benefit from attending training courses. It includes 7 items (Questions from 1 to 7).

Part (2): Knowledge about infection control in hemodialysis. Pre/posttest questionnaire sheet for the nurses: It was constructed by the researcher based on current national and international literature (Bazilay et al.,2013, Brinsley, 2017, Al Salmi et al., 2015). to assess their knowledge about infection control in hemodialysis. Which include 25 questions. It was used prior to implementation of the educational nursing program to measure the exact knowledge level of nurses regarding infection control in hemodialysis. The same tool was used immediately after the implementation of the educational nursing program (immediate post- test). The questionnaire sheet was administered by the researcher to the nurses for answering all its components then collected.

\section{Scoring system}

This questionnaire includes 25 questions: that uses a 3 -point Likert scale. Scores assigned to each item are between 0 and 2 points as follows; (don't known $=0$, in correct $=1$, and correct $=2$ ). According to range of total scores lie between 0-50. Considering good knowledge as $70 \%$ of the range of total score, patient were classified as: Satisfied if their total score was $>70 \%$, and were classified as poor knowledge (unsatisfied) if their total score was $<70 \%$.

Part (3): Nurses practice regarding infection control in hemodialysis. pre/posttest observational checklist for the nurses: It was developed by the researcher based on reviewing of literature (Engelkirk et al., 2011, O'Grady et al., 2011). to assess the practice about infection control of hemodialysis.

Scoring system: regarding observational checklist for the nurses: the part that uses a 4- point Likert scale. Scores assigned to each item are between 0 and 3 points as follows; (not done $=0$, not applicable $=1$, done incorrect $=2$ and done correct $=3$ ). According to range of total scores, nurses were classified as: poor practice if their total score was $<70 \%$, and were classified as good practice was $>70 \%$.

Tool (II): Educational nursing program: The educational nursing program was developed by use of literature review, researcher experience, and opinion of the medical and nursing expertise. The objective of this was to improve knowledge program the nurse's information and practices improved after implementation of this program. Consists the following; knowledge related to anatomy of the urinary system in human, kidney and its function. Provided information about definition and indications of hemodialysis, types of vascular access. Hand hygiene, protective equipment, cleaning and disinfection, handling of disposable supplies and water treatment purity and testing, included information's about infection control in pre hemodialysis. Information about vaccination of health care workers, cleaning and disinfection of environmental surfaces and external surfaces of hemodialysis machines, disinfection of the internal fluid pathway of hemodialysis machines, cleaning and disinfection of auxiliary equipment, handling of disposable supplies and reusable items in HD units.

Tool ( III) : Evaluation tool

Used to assess the effect of educational nursing program using tool I part 2 and part3 (knowledge and practice

Technique of data collection

This study was carried out in three phases: 
Phase I: preparatory phase: (assessment and planning phase) involved the following; review of relevant literature: nursing textbooks, journals, internet resources about infection control in hemodialysis. Then content and construct validity for data collection tools were carried out. Based on finding of the assessment, the educational nursing program was developed, after extensive literature review considering nurses needs and their level of understanding.

\section{Phase II: Implementation phase}

Data were collected from hemodialysis unit at Om ElKosoar, Assiut University Hospital during the period from June to December 2017. The tools filled through interviewing, the purpose of the study was explained to the nurses prior to answering the questions. The study was carried out at morning, and afternoon shifts. At initial interview the researcher introduce herself to initiate line of communication, explain the nature \& purpose of the nursing education program and fill out the questionnaire sheet (tool I) to assess nurse's knowledge before application of the nursing education program. Also she scheduled with them the teaching session for both theory and practice and the nurses were divided into small groups, each group contains 5 nurses. The nursing education program has been implemented for nurses in terms of sessions and teaching on the spot during their official working hours. There were a total of 7 sessions.

Number of nurses in each session 5 nurses. The duration of each session was 20-30 Minutes, including 5 minutes for feedback. Each session usually started by a summary of what has been taught during the previous sessions and the objectives of the new topics. Feedback and reinforcement of nursing education program was performed according to the nurses needs to ensure their understanding. Each nurse obtained a copy of the educational nursing program booklet that included all the training contents. This booklet is Arabic langue The objective of this booklet was to improve knowledge nurse's information and practices after implementation of this program. It consists of the following; knowledge related to anatomy of the urinary system in human, kidney and its function, definition and indications of hemodialysis, and types of vascular access. Hand hygiene, protective equipment, cleaning and disinfection, handling of disposable supplies and water treatment purity and testing, it also included information about infection control pre hemodialysis. Information about vaccination of health care workers, cleaning and disinfection of environmental surfaces and external surfaces of hemodialysis machines, disinfection of the internal fluid pathway of hemodialysis machines, cleaning and disinfection of auxiliary equipment, handling of disposable supplies and reusable items in HD units.

Phase III: Evaluation Phase: The last phase of educational nursing program is the evaluation phase. Immediately after program implementation nurses' knowledge and practices has been evaluated by the researcher though filling the tool .

Tool (1): self-administered questionnaire sheet .

(2):education nursing program .

(3): evaluation tool.

\section{Content validity}

It was established by panel of 5 expertise who reviewed the tools for clarity, relevance, comprehensiveness, understanding, applicability for pilot study and easiness for administration minor modifications were required. The content validity of this tool was checked by expert professors in the fields of medicine and nursing and correction was carried out accordingly.

A pilot study: Carried out in May 2017 to evaluate the clarity and applicability of the study tools on $10 \%$ of the sample. It had also provided an estimate of needed time to fill out the tools. The purpose of the pilot study was, to

- Ascertain the relevance of the tools.

- Detect any problem peculiar to the statements clarity that might interfere with the process of data collection.

- Estimate the time needed to complete the interview schedule.

Administrative design: An official letter was issued from the Dean of the faculty of Nursing to the Head of kidney dialysis unit soliciting the necessary approval to conduct the present research. After explaining the aims of the study and the program to explain the objective and contents the nurses consent for participation in this was obtained study.

Ethical consideration: Research proposal was approved from ethical committee in the faculty of nursing.

- There is no risk for study subject during application of the research.

- The study followed common ethical principles in clinical research.

- Oral consent was obtained from nurses who were willing to participate in the study, after explaining the nature and purpose of the study.

- Confidentiality of the collected data was assured .

- Study subject have the right to refuse to participate and or withdraw from the study without any rational any time.

Study subject privacy and anonymity were considered during collection of data.

Statistical design

The Statistical package for (SPSS) version (23) was used to analyze data. Descriptive statistics was used 
for the quantitative data in all questionnaires and the demographic data. Descriptive statistics included: Mean, standard deviation, frequencies, and percentages. Use Pearson chi-square (cross tabs test) between pre and posttest knowledge of nurses were done, independent t-test for mean score of checklist and One way a nova t-test. The level of significance for this xstudy was set at $(\mathrm{p}=0,05)$ to detect any indication of differences found in the data available

\section{Results}

Table (1): Distribution for nurses regarding personal characteristics $(n=51)$.

\begin{tabular}{|c|c|c|}
\hline Variables & N. & $\%$ \\
\hline \multicolumn{3}{|l|}{ 1. Age groups: } \\
\hline$-\quad<20 y r s$ & 4 & 7.8 \\
\hline$-\quad 20<30 y r s$ & 47 & 92.2 \\
\hline$-\quad>30 y r s$ & --------- & ------------- \\
\hline \multicolumn{3}{|l|}{ 2. Sex } \\
\hline - Male & 1 & 2.0 \\
\hline - Female & 50 & 98.0 \\
\hline \multicolumn{3}{|l|}{ 3. Level of education } \\
\hline - Diploma of Nursing & 10 & 19.6 \\
\hline$-\quad$ Institute of Nursing & 39 & 76.5 \\
\hline$-\quad$ Bachelor of Nursing & 2 & 3.9 \\
\hline \multicolumn{3}{|l|}{ 4. Years of experience in dialysis unit } \\
\hline$-<5 y r$ & 26 & 51.0 \\
\hline$-\quad 5<10 \mathrm{yrs}$ & 13 & 25.5 \\
\hline$-\quad 10$ and more & 12 & 23.5 \\
\hline \multicolumn{3}{|l|}{ 5. $\quad$ Training course in dialysis } \\
\hline- Yes & 15 & 29.4 \\
\hline$-\quad$ No & 36 & 70.4 \\
\hline \multicolumn{3}{|c|}{ 6. Benefit from attending training course } \\
\hline$-\mathrm{No}$ & 21 & 41.2 \\
\hline- Weak & 0 & 0.0 \\
\hline- Good & 19 & 37.3 \\
\hline - Very good & 11 & 21.6 \\
\hline Total & 51 & 100 \\
\hline
\end{tabular}

Table (2): Knowledge level for nurses about infection $(n=51)$.

\begin{tabular}{|c|c|c|c|c|c|c|c|}
\hline \multirow{3}{*}{ Nurses knowledge regard infection } & \multicolumn{6}{|c|}{ Knowledge pre and post program } & \multirow{3}{*}{$\begin{array}{c}\text { p. } \\
\text { value }\end{array}$} \\
\hline & \multicolumn{2}{|c|}{ Pre } & \multicolumn{2}{|c|}{ Post } & \multicolumn{2}{|c|}{ Total } & \\
\hline & $\mathbf{N}$ & $\%$ & $\mathbf{N}$. & $\%$ & $\mathbf{N}$. & $\%$ & \\
\hline \multicolumn{8}{|l|}{ 1. Infection occurs in the dialysis unit by } \\
\hline - Don't know & 10 & 9.8 & 3 & 2.9 & 13 & 12.7 & \multirow{3}{*}{0.06} \\
\hline - $\quad$ In Complete correct & 1 & 1.0 & 0 & 0.0 & 1 & 1.0 & \\
\hline - Complete correct & 40 & 39.2 & 48 & 47.1 & 88 & 86.3 & \\
\hline \multicolumn{8}{|c|}{ 2. Sources of infection within hemodialysis unit are } \\
\hline$-\quad$ Don't know & 3 & 2.9 & 1 & 1.0 & 4 & 3.9 & \multirow{3}{*}{0.30} \\
\hline - $\quad$ In Complete correct & 0 & 0 & 0 & 0 & 0 & 0 & \\
\hline$-\quad$ Complete correct & 48 & 47.1 & 50 & 49.0 & 98 & 96.1 & \\
\hline \multicolumn{8}{|c|}{ 3. Methods of infection spread within hemodialysis } \\
\hline- Don't know & 8 & 7.8 & 1 & 1.0 & 9 & 8.8 & \multirow{3}{*}{$0.01 *$} \\
\hline - $\quad$ In Complete correct & 0 & & 0 & 0 & 0 & 0 & \\
\hline$-\quad$ Complete correct & 43 & 42.2 & 50 & 49.0 & 93 & 91.2 & \\
\hline
\end{tabular}




\begin{tabular}{|c|c|c|c|c|c|c|c|}
\hline \multirow{3}{*}{ Nurses knowledge regard infection } & \multicolumn{6}{|c|}{ Knowledge pre and post program } & \multirow{3}{*}{$\begin{array}{c}\text { p. } \\
\text { value }\end{array}$} \\
\hline & \multicolumn{2}{|c|}{ Pre } & \multicolumn{2}{|c|}{ Post } & \multicolumn{2}{|c|}{ Total } & \\
\hline & N. & $\%$ & N. & $\%$ & N. & $\%$ & \\
\hline \multicolumn{8}{|c|}{ 4. Causes of the spread of infection within hemodialysis } \\
\hline- Don't know & 11 & 10.8 & 3 & 2.9 & 14 & 13.7 & \multirow{3}{*}{$0.02 *$} \\
\hline _ $\quad$ In Complete correct & 0 & 0 & 0 & 0 & 0 & 0 & \\
\hline$-\quad$ Complete correct & 40 & 39.2 & 48 & 47.1 & 88 & 86.3 & \\
\hline \multicolumn{8}{|c|}{ 5. Important ways to control the spread of infection with in hemodialysis } \\
\hline- Don't know & 2 & 2.0 & 1 & 1.0 & 3 & 2.9 & \multirow{3}{*}{0.500} \\
\hline - $\quad$ In Complete correct & 0 & 0 & 0 & 0 & 0 & 0 & \\
\hline$-\quad$ Complete correct & 49 & 48.0 & 50 & 49.0 & 99 & 97.1 & \\
\hline
\end{tabular}

Table (3): Total knowledge score for nurses regarding infection control of hemodialysis $(n=51)$ at pre and post program.

\begin{tabular}{|l|c|c|}
\hline \multicolumn{2}{|c|}{ Total knowledge } & \multirow{2}{*}{ p. value } \\
\hline & Mean \pm SD & \\
\hline Total knowledge pre & $66.41 \pm 11.14$ & \multirow{2}{*}{$0.00 * *$} \\
\hline Total knowledge post & $90.78 \pm 9.17$ & \multirow{2}{*}{} \\
\hline
\end{tabular}

Table (4) : Total practice score for nurses about infection control of hemodialysis $(n=51)$ at pre and post program.

\begin{tabular}{|l|c|c|}
\hline & Mean \pm SD & Pvalue \\
\hline \multicolumn{2}{|c|}{ Total predialysis } & \multirow{2}{*}{$0.00^{* *}$} \\
\hline Pre & $287.92 \pm 20.67$ & \\
\hline Post & $342.96 \pm 8.50$ & \multirow{2}{*}{$0.00^{* *}$} \\
\hline \multicolumn{3}{|c|}{ Total intradialysis } \\
\hline Pre & $188.25 \pm 17.41$ & \multirow{2}{*}{$0.00^{* *}$} \\
\hline Post & $247.76 \pm 5.28$ & \\
\hline Pre $\mathrm{n}=51$ & $194.07 \pm 20.16$ & Total post dialysis \\
\hline Post $\mathrm{n}=51$ & $239.62 \pm 9.24$ & \\
\hline
\end{tabular}

Table (1): This table demonstrates that the majority the sample, their age range between 20-30 years female. As regard level of education more than two thirds of the sample about (76.5\%) was having nursing Institute. As regard years of experience half of the sample $(51.0 \%)$ was less than 5 years. More than two thirds (70\%) of the sample hadn't attained training in the field. More than one third of the sample (37\%) had good benefit from attending training course.

Table (2): This table shows that; there was a statistically significant difference between pre and post program as regard methods of infection spread within hemodialysis and causes of the spread of infection within hemodialysis.

Table (3): This table show that: there was a highly statistically significant difference as regard total knowledge score for nurses about infection control of hemodialysis in pre and post program.
Table (4): This table demonstrate that: there was a highly statistically significant difference as regard total practice score for nurses about infection control pre dialysis, intra dialysis and post dialysis.

\section{Discussion}

Patients undergoing hemodialysis are at risk for infection with bloodborne viruses (primarily the hepatitis $\mathrm{B}$ and $\mathrm{C}$ ), bacterial infections caused by contamination of dialysis fluids and equipment, and other bacterial or fungal infections (e.g., pneumonia, urinary tract infection, and vascular access site infection). These patients have well-described immune deficits and require frequent hospital admission and surgery, which may increase their exposure to potential pathogens (Kadium, 2015).

Hemodialysis machines are the devices with risk of infection. Disinfection and sterilization are the main parts of the infection control in the hemodialysis units. The objective of disinfection of the 
hemodialysis system is to kill all microorganisms or to decrease the number of them. All disinfection processes performed in the hemodialysis units are traced by the Health Ministry. So that, it is planned to determine the conformities and to take the required preventions without harming the patient (Kim et al., 2011).

The aims of this study were to assess nurses' knowledge \& practice about infection control during hemodialysis, design an educational nursing program about infection control during hemodialysis, implement \& evaluate the effect of the educational nursing program about infection control during hemodialysis.

The present study finding show that as regard age; the majority of sample their age range between twenty to less than thirty years. As regard sex; the majority of them were female. This comes in agreement with (Ahmed, 2011) who mentioned that; the majority of the sample of nurses, their age ranged between twenty to less than thirty years. Also in agreement with (Hassona, 2011) who conducted a study in Hemodialysis Unit at Zagazig University Hospitals, and stated that the majority of the nurses were between ages twenty to less than thirty years. While this is in contrast with (El-Moghazy, 2013) who stated that more than half of nurses aged more than thirty years.

Concerning to level of education; more than two thirds of nurses in the current study had nursing institute. This is in agreement with (ThomasHawkins. et al., 2008) who reported that two thirds of nurses had nursing institute. While this study result is in contrast with (Ali, 2013) who reported that half of nurses in his study had diploma of nursing.

The results of the current study showed that; there was a highly statistically significant difference as regard total knowledge score for nurses about infection control of hemodialysis in pre and post program. This is in agreement with (Ahmed. et al., 2010) who reported good improvement in the knowledge scores after the application of the educational nursing program.

The current study showed that; there was a highly statistically significant difference as regard the comparison between knowledge level pre and post implementing the nursing education program. This agree with (Thomas, 2014) who mentioned that; nurse's knowledge had improved after application of an educational nursing program

Regarding nurse's total practice about infection control of hemodialysis the results of the current study revealed that majority of nurses had improvement in practice about infection control after implementation of an educational nursing program, this is in agreement with (EL-Shahed et al., 2013) who reported that; there was a highly statistically significant difference as regard total practice score for nurses about infection control pre dialysis, intra dialysis and post dialysis.

\section{Conclusions}

Based on the findings of the present study, it can be concluded that there was a highly significant difference and improvement as regard knowledge level and practice score for nurses about infection control pre dialysis, intra dialysis and post dialysis after implementing the nursing education program.

\section{Recommendations}

Based on the findings of the present study the following recommendations are suggested:

1. Schedule in-service training programs for all practice nurses that include information about infection control measures related to pre, intra and post dialysis which should be available and implemented for all nurses working in hemodialysis unit.

2. Training courses to provide nurses information about vaccination of health care workers, cleaning and disinfection of environmental surfaces and external surfaces of hemodialysis machines, disinfection of the internal fluid pathway of hemodialysis machines, cleaning and disinfection of auxiliary equipment, handling of disposable supplies and reusable items in HD units. Pamphlets and simple illustration booklets should be available for nurses to provide them knowledge and practice about infection control in hemodialysis unit.

3. An in-service education center should be established within Assiut University hospital to improve nursing staff level of knowledge and performance about infection control in hemodialysis.

4. The hemodialysis unit must be providing auxiliary equipment, handling of disposable supplies and personal protection equipment.

\section{References}

1. Ahmed A., Allam M., Habil, E., Metwally A., Ibrahiem N., Radwan M., EL-Gaafary M., Afif M. \& Gadallah M., (2010): Development of Practice Guidelines for Hemodialysis in Egypt. Indian J. Nephrol., (20) .Pp.193-202.

2. Ahmed, G., (2011): Effect of Designed Nursing Protocol on Nurse's Knowledge and Practice Regarding Hemodialys Patients. Unpublished Master Thesis, Department of Medical Surgical Nursing Science. Faculty of Nursing, Asuit University, Pp .53. 
3. Al Salmi S., Al Kubati S., Ahmed N., Mohamed O., Fayed A., \& Asfour A., (2015): Health care workers' knowledge and practices regarding the prevention of central venous catheter-related infection. Am J Infect Control (43):Pp.26-30.

4. Bazilay, E., Schaad, N., \& Magloire, R., (2013): Cholera surveillance during the Haiti epidemic: The first two years. New England Journal of Medicine (6):Pp599-609.

5. Brinsley R., (2017): A new partnership to prevent hemodialysis related infection 35.Pp 2012-2013

6. El-Moghazy G., (2013): Nurses Knowledge and Practice Regarding Intradialytic Complications for Hemodialysis Patient. Journal of American Science, Pp.9: 11.

7. Engelkirk P., Engelkirk J., \& Burton G., (2011): Burton's Microbiology for the Health Sciences microbiology for the health sciences. chapter 12, health care epidemiology, Lippincott Williams \& Wilkins, Pp. 212.

8. EL-Shahed A., ASharf S., EL Sebaee H., \& Roshdy M., (2013): Hemoglobin Level, Associated Co-Morbidities and Quality of Life among Patients Undergoing Hemodialysis at One of the University Hospitals in Cairo Governorate. World Applied Sciences Journal,( 23):Pp.29-36.

9. Fauci A., Kasper D., Longo D., (2012): Harrison's Principles Of Internal Medicine, 17th edition. Chaper 48. Acidosis and Alkalosis. 2008, The McGraw-Hill Companies, Inc. Accessed August 5, 2012

10. Hassona F., (2011): Evaluation of an Educational Program: A Report from the Hemodialysis Unit in Zagazig Univer-sity Hospitals, Egypt. Nephrology Nursing Journal, Pp.39: 53.

11. Kadium M., (2015): Improving nurses' knowledge to reduce catheter-related bloodstream infection in Hemodialysis Unit. Published Doctoral of Nursing Practice, Walden University, College of Health Sciences; 2016. pp. 5-23.

12. Kim J., Holtom P., \& Vigen C., (2011): Reduction of catheter-related bloodstream infections through the use of a central venous line bundle: epidemiologic and economic consequences. Am J Infect Control 39:Pp.40 646.

13. Lioselle, M., Connor A., \& Michaud C, (2011): Developing a Decision Support intervention regarding choice of dialysis modality. Conadian Association of Nephrology Nurses and Technologists Journal, 121 (93). Pp.13-18.

14. Napalkov P., Chu L., Jacobs J., \& Begelman S., (2013): Incidence of catheter-related complications in patients with central venous or hemodialysis catheters:health care claims database analysis.(13):Pp 13-86.

15. O'Grady N., Alexander M., Burns L., Dellinger E., Gerberding J., \& Heard S., (2011): Centers for Disease Control and Prevention guidelines for the prevention of intravascular catheter-related infections. Clin Infect Dis 52pp1-32.

16. Patel P., Kallen A., Arduino M., (2010): Epidemiology, surveillance, and prevention of bloodstream infections in hemodialysis patients. Am J Kidney Dis 56:Pp566-577.

17. Rosenthal J., Maki D., Jamulitrat S., Medeiros E., Todi S., \& Gomez D., (2010): International Nosocomial Infection Control Consortium (INICC) 38:Pp95-104.

18. Thomas N., (2014): Renal Nursing. Chronic renal diseaese and hemodialysis., Elsevier Health Sciences, 4th ed, 8: pp.166-7, 2014. 